\title{
Plasma rich in growth factors (PRGF) in non-surgical periodontal therapy: a randomized clinical trial
}

\author{
Saurav PANDA ${ }^{(a)}$ ID \\ Adrita PURKAYASTHA(a) iD \\ Rinkee MOHANTY(a) iD \\ Rashmita NAYAK(a) ID \\ Anurag SATPATHY(a) iD \\ Abhaya Chandra DAS(a) ID \\ Manoj KUMAR(a) iD \\ Gatha MOHANTY(a) ID \\ Sital PANDA(b) iD \\ Massimo Del FABBRO(c) iD \\ (a) Siksha $\bigcirc$ Anusandhan University, Institute of \\ Dental Sciences, Department of Periodontics \\ \& Oral implantology, Bhubaneswar, \\ Odisha, India. \\ (b)Private Practice, Bhubaneswar, India. \\ (c) University of Milan, Department of \\ Biomedical, Surgical \& Dental Sciences, \\ Milano, Italy.
}

Declaration of Interests: The authors certify that they have no commercial or associative interest that represents a conflict of interest in connection with the manuscript.

Corresponding Author:

Saurav Panda

E-mail:drsaurav87@gmail.com

hitps://doi.org/10.1590/1807-3107bor-2020.vol34.0034

Submitted: November 16, 2019

Accepted for publication: February 12, 2020

Last revision: March 11, 2020

\begin{abstract}
The aim of this split mouth, double blinded, randomized clinical trial was to evaluate the clinical efficacy of use of Plasma rich in growth factors (PRGF) as an adjunct to scaling and root planing (SRP) in the treatment of periodontal pockets. Twenty six patients (15 males, 11 females) diagnosed with generalized periodontitis with Pocket Depth $>5 \mathrm{~mm}$ and plaque index score $<1.5$, were randomly allocated by using computer generated random sequence, into two groups, one treated with intra-pocket application of PRGF adjunct to SRP and other with SRP alone. The clinical outcomes like pocket depth (PD), relative attachment level (RAL) and sulcus bleeding index (SBI) were assessed at baseline, 3 months and 6 months. Twenty two patients (44 sites) were analyzed at the end of 6 month follow-up, using SPSS 20.0v software. There was a significant statistical difference observed between both the groups favouring SRP +PRGF group in terms of PD $(p=0.007)$ and RAL $(p=0.021)$ at the end of 6 month follow-up. Also there was a statistical significant difference $(<0.001)$ at all time points compared to baseline, for all parameters in intra-group comparison. Moreover, the sites with PD $>4 \mathrm{~mm}$ necessitating further treatment after 6-month follow-up were significantly lesser for SRP+PRGF group. The use of PRGF technology in non-surgical periodontal therapy, by single intra-pocket application in to periodontal pockets as an adjunct to SRP, in chronic periodontitis patients, was found to be effective in reduction of pocket depth and gain in clinical attachment level.
\end{abstract}

Keywords: Blood Platelets; Regeneration; Wound Healing.

\section{Introduction}

Periodontal disease is an inflammatory destruction of the supporting structures of teeth caused by pathogenic bacteria leading to loss of epithelial attachment. ${ }^{1}$ Treatment of periodontal disease always begins with the reduction of periodontal pockets and elimination of the inflammation. The primary goal of periodontal therapy is to eliminate microbial plaque and calculus and allow the periodontal tissues to heal. ${ }^{2}$ Proper debridement of plaque and calculus from the periodontal pockets can be achieved by the use of non-surgical approaches such as scaling and root planing (SRP). Once this is accomplished, surgical part of the treatment could be initiated when indicated. ${ }^{3}$ 
Non-surgical periodontal treatment (NSPT) such as SRP aids in improvement and maintenance of the periodontal health with a conservative approach. Various studies have illustrated the efficacy of SRP in maintenance of healthy periodontium. ${ }^{4,5}$ However, deep periodontal pockets are a deterrent to effectiveness of the NSPT due to incomplete debridement in inaccessible deep pocket areas. ${ }^{6}$

Over the years, NSPT has been carried out by a wide array of adjuncts with SRP for effective treatment and maintenance of periodontal health in such deep periodontal pockets. Local drug delivery systems like use of antimicrobials, essential oils, anti-oxidants and plant extracts have been used as an adjunct to SRP in treatment of these periodontal pockets with varying success. $7,8,9,10,11$

Polypeptide growth factors such as platelet derived growth factor (PDGF), vascular endothelial growth factor (VEGF), insulin-like growth factor (IGF) and transforming growth factor (TGF) improved the clinical and radiological outcome, especially in surgical treatment of periodontal intrabony defects. ${ }^{12,13}$ Since they have been known to promote wound healing and epithelisation, they may also aid in early resolution of chronic inflammatory lesions such as periodontal pockets and prove beneficial in nonsurgical periodontal therapy as well. ${ }^{7,14}$

Autologous platelet concentrates (APCs) are gaining popularity in many clinical scenarios, as it acts as a reservoir for an array of growth factors including PDGF, VEGF, TGF, IGF etc. ${ }^{15,16,17}$ The contribution of platelets to soft tissue and hard tissue regeneration is based on various growth factors stored in the alpha granules and their release upon physiologic activation.

Plasma rich in growth factors (PRGF) is an autologous platelet concentrate which delivers an array of polypeptide growth factors promoting soft tissue and bone regeneration. ${ }^{18}$ The healing of periodontal pocket pertains to gain in attachment of gingival epithelium on the root surface by cellular proliferation and differentiation. Growth factors released from PRGF promote these biologic processes like proliferation, migration and differentiation at the cellular level. ${ }^{19}$ PRGF is a second generation system, similar to that of platelet rich plasma (PRP), used for obtaining platelets and plasma proteins and has unique advantages as it needs less venous blood, is more convenient, less time consuming, safe, easy to use and induces faster healing. ${ }^{20}$

However, the clinical effects and benefits of the use of PRGF in periodontal healing is poorly understood and not well investigated. Furthermore, to our knowledge no clinical studies are reported till date that investigates the efficacy of PRGF in NSPT. Therefore, the aim of this randomized clinical trial was to investigate the clinical efficacy of use of PRGF as an adjunct to SRP in terms of gain in attachment level and pocket depth reduction in the treatment of periodontal pockets.

\section{Methodology}

\section{Study population}

Twenty-six patients (15 males, 11 females), with an age range of 30-50 years (mean age of $35.8+$ 12.7), suffering from Generalized periodontitis with stage III \& Grade A or B with no risk factor and currently unstable periodontal status (PPD $>5 \mathrm{~mm}$ and presence of bleeding on probing), based on the latest AAP classification criteria, $2017^{21}$ were recruited for this double blinded randomized, split-mouth, clinical trial with follow-up of 6 months. The study was conducted between January 2018 to April 2019, with the patients reporting to the out-patient Department of Periodontics, Institute of Dental Sciences, Bhubaneswar, India. The study was designed to follow the principles of the Declaration of Helsinki of 1975 , as revised in 2008. The ethical approval was obtained from Institutional Ethical Committee of Siksha O Anusandhan University. All patients were detailed about the protocol, study benefits and its risk along with treatment procedures before commencement of the trial and an informed written consent was taken.

Patients presenting with two contra-lateral sites with probing depth $\geq 5 \mathrm{~mm}$ associated with premolar and molar teeth with no furcation involvement, full mouth plaque index score $<1.5^{22}$ having no systemic disease or debilitating conditions, or use of any medications which could affect the outcome of periodontal therapy, with no history of any periodontal 
therapy within past 6 months were included. Pregnant and lactating mothers, smokers smoking $>10$ cigarettes per day and patients with blood disorders or platelet count less than 50000 cells/ $\mu 1$ were excluded from the study.

\section{Randomisation, blinding and allocation}

All the patients were subjected to randomization of test (PRGF + SRP) and control (SRP alone) sites by using computer generated random sequence. The test site received single intra-pocket application of PRGF following thorough SRP, while the control site received SRP alone. This trial was designed as double blinded randomized clinical trial, where both the investigator and assessor were blinded. The allocation of the treatment protocol for the patient in respective group was written in a sealed envelope and was opened after administering SRP for all patients. A single clinician (SP) performed SRP for all the patients. A single session of SRP was carried out using ultrasonic scaler (Acteon Satelac P5 Booster scaler,Acteon, Germany, EU) during the entire follow-up period of 6 months.

\section{Preparation and delivery of PRGF}

PRGF was prepared according to below mentioned protocol. ${ }^{18}$ Nine millilitres of blood were drawn from each patient into vacutainers containing 10\% trisodium citrate. The vacutainers were centrifuged (BTI-Endoret System IV Centrifuge, Biotechnology Institute, Vitoria, Spain) to separate the blood into its 3 layers: red blood cells (RBCs),sediment at the

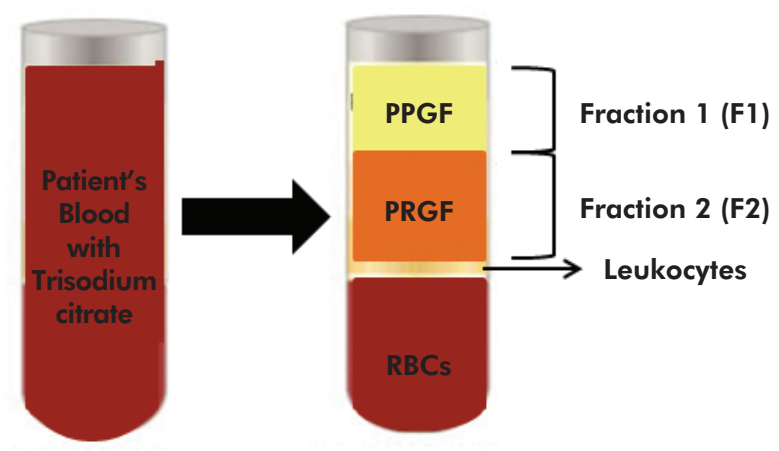

bottom of the test-tube; PRGF in the middle of the test-tube just above the buffy coat layer; and plasma poor in growth factors (PPGF) at the top of the testtube (Figure 1). The top fraction containing PPGF was labelled as fraction 1 (F1) and middle portion was labelled as fraction 2 (F2). The F2 (PRGF) was collected from each tube using a pipette. ${ }^{18}$ The F2 was activated with $0.2 \mathrm{ml} 10 \%$ Calcium Chloride and transferred to a $5 \mathrm{ml}$-syringe to form PRGF F2 gel. The PRGF F2 gel was then pistoned out through the blunt cannula in the deeper pockets of the test sites. The delay between the PRGF gel preparation and intra-pocket application was fixed at 5 to 10 minutes. The test group site alone received PRGF F2 gel by an independent investigator (A.P).

\section{Outcome variables}

The primary outcome measure was Probing Depth (PD) reduction and secondary outcome measure were Relative Attachment Level (RAL) and Sulcus Bleeding Index (SBI). ${ }^{23}$ For baseline and follow-up measurements of RAL and PD, UNC-15 periodontal probe (Hu-Friedy Mfg. Inc, Chicago, IL, USA) was used. All the outcome measure recordings were made at baseline, 3 and 6 months. The marking made at lower border of the occlusal stent placed on the study tooth was used as a reference point for recording RAL. All the baseline and follow-up measurements were made by an independent examiner (R.M) who was blinded to site receiving test treatment.

Post SRP oral hygiene instructions were given and reinforced at all follow-up time points. No antibiotics

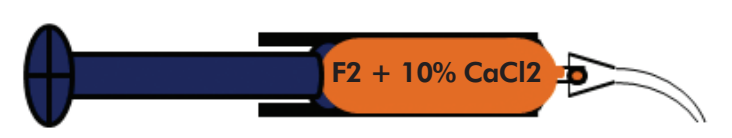

Figure 1. Schematic representation of PRGF F2 Gel used for intra-pocket application. 
and anti-microbial agents were prescribed throughout the study period.

\section{Statistical analysis}

The statistical software SPSS version 20 (SPSS, Chicago, USA) was used to carry out the analysis of collected data. One site in the experimental region (surface) and one site in the control region (surface) with deepest pocket depth and RAL at baseline were used for the statistical analysis. Data were expressed as means \pm standard deviations (SD). To achieve $80 \%$ power at $95 \%$ confidence level and to detect mean differences of $1 \mathrm{~mm}$ in the PD and RAL between test and control sites, 21 sites per group were necessary. 25 sites per group were considered to account for possible loss during follow-up. Paired-t test was used to analyse intra and inter-group differences for the outcomes at various time points. McNemar test was employed to compare the probing depth assessment between the SRP + PRGF and SRP groups. D'Agostino and Pearson's omnibus normality test was carried out to check the normality of the distribution. The level of significance was set at $\mathrm{p}<0.05$.

\section{Results}

Twenty-six patients with two contra-lateral pockets $>5 \mathrm{~mm}$ were selected for the study. All patients showed acceptable plaque index following SRP and maintained throughout the study. No complications were reported in sites with PRGF gel. The study started with 26 patients (52 sites) but only 22 patients (44 sites) could be evaluated at the end of the 6- month follow-up visit. The details of the patient's enrollment, allocation and analysis are described in CONSORT flow diagram (Figure 2). Four

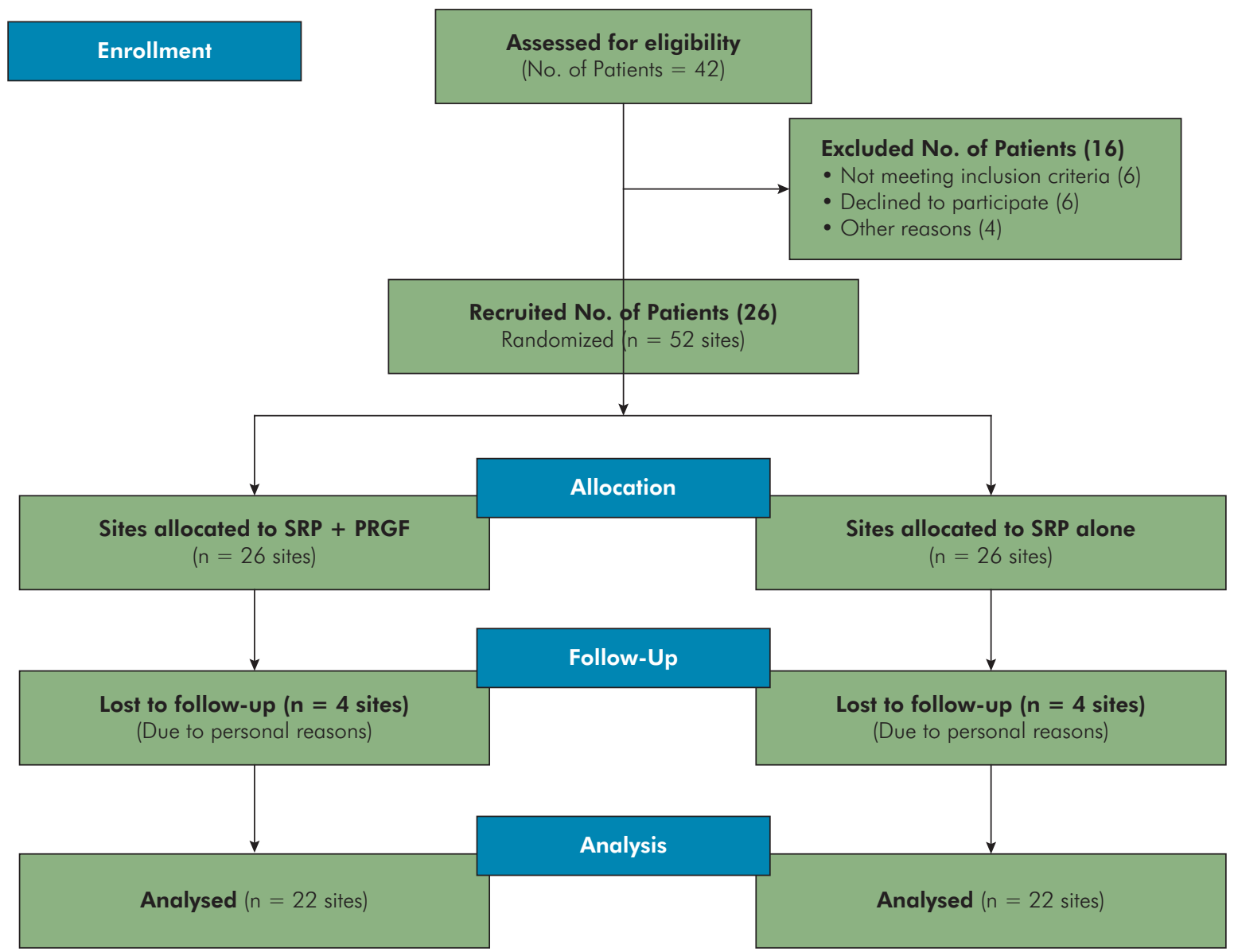

Figure 2. Consort flow diagram. 
patients could not complete the whole study period and did not show at the follow-up due to personal reasons, however, the data of all patients were recorded for intermediate 3-month follow-up visit.

Table 1 presents the inter-group comparison of PD, RAL and SBI, for the sites treated with SRP + PRGF (test) and SRP alone (control) at all three time points with improvement in test group compared to control. There was a significant statistical difference observed between both the groups favouring SRP + PRGF group in terms of PD $(p=0.007)$ and RAL $(p=0.021)$ at the end of 6month follow-up. However, no statistical significant difference was observed for SBI $(p=0.427)$ between both the groups at 6 month follow-up.

Table 2 presents the intra-group comparison for all parameters showing highly significant improvement $(\mathrm{p}<0.001)$ for PD, RAL and SBI, both at 3 months and 6 months compared to baseline, for both groups. A statistical significant difference $(<0.001)$ at all time points ( 3 months and 6 months) compared to baseline was noticed and also for difference in values for 6 month follow-up compared to 3 month for both groups, except for SBI $(p=0.054)$ for SRP+PRGF group.

Table 3 shows the distribution of sites as per probing depths at baseline and after treatment. It was observed that although after 3 months, a comparable reduction in $\mathrm{PD}<4 \mathrm{~mm}$ was observed in both groups, after 6 months $90.9 \%$ of the sites reduced to $<4 \mathrm{~mm}$ in SRP+PRGF group as compared to $59.1 \%$ in the SRP alone group.

After excluding the data of the patients who couldn't complete the study, it was found that in the SRP+ PRGF group, out of 14 sites that had PD $>4 \mathrm{~mm}$ at 3 months, 12 sites had PD $<4 \mathrm{~mm}$ at 6 months. However, in the SRP alone group, out of 16 sites that had PD $>4 \mathrm{~mm}$ at 3 months only 7 sites had

Table 1. Inter-group comparison of clinical outcomes between SRP +PRGF versus SRP alone at baseline, 3 and 6 months.

\begin{tabular}{|c|c|c|c|c|c|c|c|c|}
\hline \multirow{2}{*}{ Time } & \multirow{2}{*}{ Groups } & \multirow{2}{*}{$\mathrm{n}$} & \multirow{2}{*}{ Mean } & \multirow{2}{*}{ SD } & \multicolumn{2}{|c|}{$95 \% \mathrm{Cl}$} & \multirow{2}{*}{$t$} & \multirow{2}{*}{${ }^{*} p$-value } \\
\hline & & & & & Lower & Upper & & \\
\hline \multicolumn{9}{|l|}{ PD } \\
\hline \multirow{2}{*}{ At Baseline } & $\mathrm{SRP}+\mathrm{PRGF}$ & 25 & 5.80 & 0.91 & -0.71 & -1.06 & 0.23 & 0.298 \\
\hline & SRP alone & 25 & 6.04 & 0.84 & & & & \\
\hline \multirow{2}{*}{ After 3 months } & $\mathrm{SRP}+\mathrm{PRGF}$ & 25 & 4.72 & 0.84 & -0.62 & -0.50 & 0.38 & 0.622 \\
\hline & SRP alone & 25 & 4.84 & 0.80 & & & & \\
\hline \multirow{2}{*}{ After 6 months } & $\mathrm{SRP}+\mathrm{PRGF}$ & 22 & 3.59 & 0.67 & -1.08 & -2.98 & -0.19 & 0.007 \\
\hline & SRP alone & 22 & 4.23 & 0.87 & & & & \\
\hline \multicolumn{9}{|l|}{ RAL } \\
\hline \multirow{2}{*}{ At Baseline } & $\mathrm{SRP}+\mathrm{PRGF}$ & 25 & 11.48 & 1.48 & -0.92 & -0.31 & 0.68 & 0.760 \\
\hline & SRP alone & 25 & 11.60 & 1.44 & & & & \\
\hline \multirow{2}{*}{ After 3 months } & $\mathrm{SRP}+\mathrm{PRGF}$ & 25 & 9.88 & 1.33 & -1.13 & -0.68 & 0.57 & 0.502 \\
\hline & SRP alone & 25 & 10.16 & 1.60 & & & & \\
\hline \multirow{2}{*}{ After 6 months } & $\mathrm{SRP}+\mathrm{PRGF}$ & 22 & 8.14 & 0.99 & -1.92 & -2.50 & -0.17 & 0.021 \\
\hline & SRP alone & 22 & 9.18 & 1.59 & & & & \\
\hline \multicolumn{9}{|l|}{ SBI } \\
\hline \multirow{2}{*}{ At Baseline } & $\mathrm{SRP}+\mathrm{PRGF}$ & 25 & 1.56 & 0.51 & -0.46 & -0.72 & 0.22 & 0.478 \\
\hline & SRP alone & 25 & 1.68 & 0.56 & & & & \\
\hline \multirow{2}{*}{ After 3 months } & $\mathrm{SRP}+\mathrm{PRGF}$ & 25 & 0.64 & 0.49 & -0.74 & -2.45 & -0.06 & 0.022 \\
\hline & SRP alone & 25 & 1.04 & 0.73 & & & & \\
\hline \multirow{2}{*}{ After 6 months } & $\mathrm{SRP}+\mathrm{PRGF}$ & 22 & 0.41 & 0.50 & -0.32 & -0.81 & 0.14 & 0.427 \\
\hline & SRP alone & 22 & 0.50 & 0.51 & & & & \\
\hline
\end{tabular}

*Paired student's + test 
Plasma rich in growth factors (PRGF) in non-surgical periodontal therapy: a randomized clinical trial

Table 2. Intra-group comparison of clinical outcomes between SRP + PRGF versus SRP alone at baseline, 3 and 6 months.

\begin{tabular}{|c|c|c|c|c|c|c|}
\hline \multirow{3}{*}{ Time Interval } & \multicolumn{4}{|c|}{ Paired Differences } & \multirow{3}{*}{$t$} & \multirow{3}{*}{${ }^{*} p$-value } \\
\hline & \multirow{2}{*}{ Mean } & \multirow{2}{*}{ SD } & \multicolumn{2}{|c|}{$95 \% \mathrm{Cl}$} & & \\
\hline & & & Lower & Upper & & \\
\hline \multicolumn{7}{|l|}{ Group: SRP + PRGF } \\
\hline \multicolumn{7}{|l|}{ PD } \\
\hline Baseline - After 3 months & 1.08 & 0.81 & 0.74 & 1.42 & 6.65 & $<0.001$ \\
\hline Baseline - After 6 months & 2.23 & 0.81 & 1.87 & 2.59 & 12.86 & $<0.001$ \\
\hline After 3 months - After 6 months & 1.18 & 0.80 & 0.83 & 1.53 & 6.97 & $<0.001$ \\
\hline \multicolumn{7}{|l|}{ RAL } \\
\hline Baseline - After 3 months & 1.60 & 1.08 & 1.15 & 2.05 & 7.41 & $<0.001$ \\
\hline Baseline - After 6 months & 3.41 & 1.22 & 2.87 & 3.95 & 13.09 & $<0.001$ \\
\hline After 3 months - After 6 months & 1.91 & 0.81 & 1.55 & 2.27 & 11.04 & $<0.001$ \\
\hline \multicolumn{7}{|l|}{ SBI } \\
\hline Baseline - After 3 months & 0.92 & 0.70 & 0.63 & 1.21 & 6.55 & $<0.001$ \\
\hline Baseline - After 6 months & 1.18 & 0.59 & 0.92 & 1.44 & 9.42 & $<0.001$ \\
\hline After 3 months - After 6 months & 0.27 & 0.63 & -0.01 & 0.55 & 2.03 & $=0.054$ \\
\hline \multicolumn{7}{|l|}{ Group: SRP alone } \\
\hline \multicolumn{7}{|l|}{ PD } \\
\hline Baseline - After 3 months & 1.20 & 0.65 & 0.93 & 1.47 & 9.30 & $<0.001$ \\
\hline Baseline - After 6 months & 1.73 & 0.63 & 1.45 & 2.01 & 12.84 & $<0.001$ \\
\hline After 3 months - After 6 months & 0.68 & 0.57 & 0.43 & 0.93 & 5.63 & $<0.001$ \\
\hline \multicolumn{7}{|l|}{ RAL } \\
\hline Baseline - After 3 months & 1.44 & 1.12 & 0.98 & 1.90 & 6.42 & $<0.001$ \\
\hline Baseline - After 6 months & 2.50 & 1.19 & 1.97 & 3.03 & 9.89 & $<0.001$ \\
\hline After 3 months - After 6 months & 1.09 & 0.29 & 0.96 & 1.22 & 17.39 & $<0.001$ \\
\hline \multicolumn{7}{|l|}{ SBI } \\
\hline Baseline - After 3 months & 0.64 & 0.81 & 0.31 & 0.97 & 3.95 & $=0.001$ \\
\hline Baseline - After 6 months & 1.23 & 0.69 & 0.92 & 1.53 & 8.40 & $<0.001$ \\
\hline After 3 months - After 6 months & 0.68 & 0.84 & 0.31 & 1.05 & 3.81 & $=0.001$ \\
\hline
\end{tabular}

*Paired Student's † test.

Table 3. Distribution of sites as per probing depths at baseline and after treatment.

\begin{tabular}{|c|c|c|c|c|c|}
\hline \multirow{2}{*}{ Probing depth } & & \multicolumn{2}{|c|}{$\mathrm{SRP}+\mathrm{PRGF}$} & \multicolumn{2}{|c|}{ SRP alone } \\
\hline & & $\mathrm{n}$ & $\%$ & $\mathrm{n}$ & $\%$ \\
\hline \multirow{2}{*}{ At Baseline } & $<4 \mathrm{~mm}$ & 0 & 0.0 & 0 & 0.0 \\
\hline & $>4 \mathrm{~mm}$ & 25 & 100.0 & 25 & 100.0 \\
\hline \multirow{2}{*}{ After 3 months } & $<4 \mathrm{~mm}$ & 10 & 40.0 & 8 & 32.0 \\
\hline & $>4 \mathrm{~mm}$ & 15 & 60.0 & 17 & 68.0 \\
\hline \multirow{2}{*}{ After 6 months } & $<4 \mathrm{~mm}$ & 20 & 90.9 & 13 & 59.1 \\
\hline & $>4 \mathrm{~mm}$ & 2 & 9.1 & 9 & 40.9 \\
\hline
\end{tabular}


Table 4. Comparison of Probing depth assessment between the SRP+PRGF and SRP groups.

\begin{tabular}{lcccc}
\hline \multirow{2}{*}{ Group } & After 3 & \multicolumn{2}{c}{ After 6 months } & \\
\cline { 3 - 4 } & months & $<4 \mathrm{~mm}$ & $>4 \mathrm{~mm}$ & \\
\hline \multirow{2}{*}{$\mathrm{SRP}+\mathrm{PRGF}$} & $<4 \mathrm{~mm}$ & 8 & 0 & 0.001 \\
& $>4 \mathrm{~mm}$ & 12 & 2 & \\
SRP & $<4 \mathrm{~mm}$ & 6 & 0 & 0.016 \\
& $>4 \mathrm{~mm}$ & 7 & 9 & \\
\hline
\end{tabular}

*McNemar's test.

$\mathrm{PD}<4 \mathrm{~mm}$ at 6 months. After 6 months, no sites in either group showed increase in PD $>4 \mathrm{~mm}$ that had a PD $<4 \mathrm{~mm}$ at 3 months. The observed change was statistically significant in SRP + PRGF $(p<0.001)$ and SRP alone $(p=0.016)$ groups (Table 4$)$.

In patients that had $\mathrm{PD}>4 \mathrm{~mm}$ at 3 months $(\mathrm{SRP}+$ PRGF: $\mathrm{n}=14$ and SRP alone: $\mathrm{n}=16$ ) a between-group comparison of the number of sites that improved PD to $<4 \mathrm{~mm}$ at 6 months $(12 / 2 \mathrm{vs} 7 / 9)$. Using the Fisher's exact test a p-value of 0.019 is obtained, indicating that the improvement was significantly better for the SRP+PRGF group.

\section{Discussion}

This randomized, split-mouth, clinical trial evaluated the use of PRGF as an adjunct to SRP for treatment of deep periodontal pockets. To the best of our knowledge, this is the first study that evaluates the effect of PRGF placed into deep periodontal pockets. The results of the present trial showed significant improvements in all outcome variables with use of PRGF as an adjunct to SRP compared to SRP alone for the treatment of deep periodontal pockets.

"Endogenous regenerative medicine" is a new concept which uses patient's own blood plasma and biologically active platelet derived growth factors and cytokines to stimulate faster wound healing along with soft and hard tissue regeneration. The application of PRP, PRGF and Platelet rich fibrin (PRF) is gaining popularity in last two decades in regeneration science. The use of these platelet concentrates are well documented in various clinical scenarios. However, the application of platelet concentrates in periodontal pockets for periodontal healing are very less studied and unclear.

Previously, there have been few studies using PRP application into periodontal pockets. We found significantly more attachment gain in sites with SRP+PRGF (3.41 $\pm 1.22 \mathrm{~mm})$ in comparison to control sites $(2.50 \pm 1.19 \mathrm{~mm})(\mathrm{p}<0.001)$ in our study, which was in accordance with a study which showed significant clinical improvement with mean CAL gain of $2.40 \pm 0.4 \mathrm{~mm}$ for control sites and $2.68 \pm 0.5 \mathrm{~mm}$ for sites treated with use of PRP as an adjunct to SRP after 6 months in the treatment of chronic periodontitis. ${ }^{14}$ PRGF compared to PRP, has an added advantage of having a gel like consistency, which could be easily delivered into the deep periodontal pockets and be retentive inside the confined pocket area. The gel like consistency, also guarantees slow release pattern of growth factors for aiding initial granulation tissue formation and epithelialization. ${ }^{24}$

PRGF is known to reduce inflammation at 28 days and accelerating epithelialisation of the wounds in the oral cavity. A histological analysis in a study assessing complete epithelialization and reduction in inflammation of the wounds at 7 and 28 days with the use of PRGF concluded that, the wounds dressed with PRGF completely epithelialized and showed significant reduction of the inflammation at the end of 28 days follow-up compared to control sites. ${ }^{25}$

The use of PRGF in healing of periodontal pockets may be attributed to its regenerative effects on human gingival fibroblasts (HGF) proliferation. An in-vitro study evaluated the effect of PRGF on proliferation and viability of human gingival fibroblasts in comparison to PRF and demonstrated the significantly stronger stimulatory effect of PRGF on proliferation and maintenance of cell viability up to 72 hours $(\mathrm{p}<0.001)$ inducing a statistically significant $(p<0.001)$ proliferation of HGF cells compared to the negative control $(100 \%$ viability) at 24, 48 and 72 hours. ${ }^{26}$ In another study, reduced keratin 1 and keratin 10 gene expression was seen in human keratinocytes primed with PRGF but the same induced transglutaminase-1 gene expression along with involucrin expression in an epidermal growth factor receptor (EGFR) - dependent manner. This typical gene expression is necessary for 
regulating terminal differentiation of primary human keratinocytes. ${ }^{27}$ PRGF has also seen to stimulate the proliferation and migration of primary keranitocytes and conjunctival fibroblasts in repair of wound on ocular surface. ${ }^{28}$ In accordance to aforementioned studies, the activated platelet concentrates also induces the proliferation of terminally differentiated human osteoblasts and dermal fibroblasts, required for soft tissue and hard tissue regeneration..$^{29}$

PRGF is also known to reduce the pro-inflammatory effect as the protocol of PRGF preparation ensures exclusion of leukocytes in the content. Both erythrocytes and leukocytes were almost completely eliminated in the process of preparation and the platelets were significantly concentrated by 2.84 fold.$^{30}$

The antimicrobial activity of PRGF has been demonstrated by its effect against the four staphylococci strains, reaching its maximum during the first few hours after application. ${ }^{31}$ Few studies which showed anti-microbial effect of pure platelet-rich plasma (P-PRP) against Enterococcus faecalis, Candida albicans, Streptococcus agalactiae, Streptococcus oralis and Pseudomonas aeruginosa, showed that P-PRP inhibited the growth of all 3 strains but not of Pseudomonas aeruginosa. ${ }^{32,33}$ In agreement with the findings of the present research, a recent study also demonstrated the clinical antiinflammatory effect of PRP by administering PRP into the periodontal pockets deeper than $4 \mathrm{~mm}$ after SRP. All clinical periodontal parameters showed a reduction in their value after 1 month of application of PRP along with a noticeable reduction in lymphocyte count. ${ }^{34}$

Numerous literature evidences the regenerative potential of autologous platelet concentrates in surgical treatment of periodontitis in combination to scaling and root planing or other biomaterials. ${ }^{35,36,37,38,39}$ Platelet-rich fibrin and Platelet-rich plasma have been used in such surgical regenerative approaches. ${ }^{40}$ Intra-pocket application of PRF and PRP, seems to be difficult due to its inability for insertion and retention into small confined pocket spaces respectively. However, PRGF due to its gel consistency seems ideal for non-surgical intra-pocket applications.

In our study, encouraging results were observed after a single intra-pocket application of PRGF. We propose that multiple applications of PRGF would be of additional value and may be studied in different populations. Application of PRGF into periodontal pockets is easy, safe and with encouraging outcome, could aid patients where surgical periodontal therapy may not be feasible. The anti-microbial effect of PRGF against various periodontopathogens in deeper periodontal pockets and effect on various inflammatory biomarkers of GCF could also be evaluated, in further studies.

\section{Conclusion}

Introduction of PRGF technology has opened newer perspectives in periodontal treatment and is a worthy advancement in regenerative science as it promotes healing of periodontal tissues. Within the study limits, the use of PRGF technology in nonsurgical periodontal therapy, by simple intra-pocket application of PRGF gel into deep periodontal pockets as an adjunct to SRP in periodontitis patients was found to be effective in reduction of pocket depth and gain in attachment level. Further studies should be carried out with larger sample size and evaluating biochemical and microbiological parameters to establish our findings.

\section{References}

1. Bartold PM, Cantley MD, Haynes DR. Mechanisms and control of pathologic bone loss in periodontitis. Periodontol 2000. 2010 Jun;53(1):55-69. https://doi.org/10.1111/i.1600-0757.2010.00347.x

2. Graves DT, Li J, Cochran DL. Inflammation and uncoupling as mechanisms of periodontal bone loss. J Dent Res. 2011 Feb;90(2):143-53. https://doi.org/10.1177/0022034510385236

3. Lindhe J, Westfelt E, Nyman S, Socransky SS, Haffajee AD. Long-term effect of surgical/non-surgical treatment of periodontal disease. J Clin Periodontol. 1984 Aug;11(7):448-58. https://doi.org/10.1111/i.1600-051X.1984.tb01344.x 
4. Heitz-Mayfield LJ, Trombelli L, Heitz F, Needleman I, Moles D. A systematic review of the effect of surgical debridement vs non-surgical debridement for the treatment of chronic periodontitis. J Clin Periodontol. 2002;29(s3 Suppl 3):92-102. https://doi.org/10.1034/j.1600-051X.29.s3.5.x

5. Caffesse RG, Sweeney PL, Smith BA. Scaling and root planing with and without periodontal flap surgery. J Clin Periodontol. 1986 Mar;13(3):205-10. https://doi.org/10.1111/j.1600-051X.1986.tb01461.x

6. Bhansali RS. Non-surgical periodontal therapy: an update on current evidence. World J Stomatol. 2014 Nov;3(4):38-51. https://doi.org/10.5321/wjs.v3.i4.38

7. Howell TH, Martuscelli G, Oringer J. Polypeptide growth factors for periodontal regeneration. Curr Opin Periodontol. 1996;3:149-56.

8. Szulc M, Zakrzewska A, Zborowski J. Local drug delivery in periodontitis treatment: A review of contemporary literature. Dent Med Probl. 2018 Jul-Sep;55(3):333-42. https://doi.org/10.17219/dmp/94890

9. Gartenmann SJ, Weydlich YV, Steppacher SL, Heumann C, Attin T, Schmidlin PR. The effect of green tea as an adjunct to scaling and root planing in non-surgical periodontitis therapy: a systematic review. Clin Oral Investig. 2019 Jan;23(1):1-20. https://doi.org/10.1007/s00784-018-2684-7

10. Di Genio M, Barone A, Ramaglia L, Sbordone L. [Periodontal regeneration: the use of polypeptide growth factors]. Minerva Stomatol. 1994 Oct;43(10):437-43. Italian.

11. Kaur S, Sharma R, Sarangal V, Kaur N, Prashar P. Evaluation of anti-inflammatory effects of systemically administered curcumin, lycopene and piperine as an adjunct to scaling and root planing: A clinical study. Ayu. 2017 Jul-Dec;38(3-4):117-21. https://doi.org/10.4103/ayu.AYU_63_17

12. Piemontese M, Aspriello SD, Rubini C, Ferrante L, Procaccini M. Treatment of periodontal intrabony defects with demineralized freezedried bone allograft in combination with platelet-rich plasma: a comparative clinical trial. J Periodontol. 2008 May;79(5):802-10. https://doi.org/10.1902/jop.2008.070436

13. Hanna R, Trejo PM, Weltman RL. Treatment of intrabony defects with bovine-derived xenograft alone and in combination with plateletrich plasma: a randomized clinical trial. J Periodontol. 2004 Dec;75(12):1668-77. https://doi.org/10.1902/jop.2004.75.12.1668

14. Agarwal A, Dev Gupta N. Platelet-rich plasma with scaling and root planing: a double blind split-mouth randomized study. J Periodontol Implant Dent. 2014 Dec;6(2):35-9. https://doi.org/10.15171/ipid.2014.007

15. Panda S, Karanxha L, Goker F, Satpathy A, Taschieri S, Francetti L, et al. Autologous platelet concentrates in treatment of furcation defects-a systematic review and meta-analysis. Int J Mol Sci. 2019 Mar;20(6):E1347. https://doi.org/10.3390/ijms20061347

16. Panda S, Doraiswamy J, Malaiappan S, Varghese SS, Del Fabbro M. Additive effect of autologous platelet concentrates in treatment of intrabony defects: a systematic review and meta-analysis. J Investig Clin Dent. 2016 Feb;7(1):13-26. https://doi.org/10.1111/jicd.12117

17. Del Fabbro M, Karanxha L, Panda S, Bucchi C, Nadathur Doraiswamy J, Sankari M, et al. Autologous platelet concentrates for treating periodontal infrabony defects. Cochrane Database Syst Rev. 2018;11:CD011423. https://doi.org/10.1002/14651858.CD011423.pub2

18. Anitua E, Murias-Freijo A, Alkhraisat MH, Orive G. Clinical, radiographical, and histological outcomes of plasma rich in growth factors in extraction socket: a randomized controlled clinical trial. Clin Oral Investig. 2015 Apr;19(3):589-600. https://doi.org/10.1007/s00784-014-1278-2

19. Anitua E. Plasma rich in growth factors: preliminary results of use in the preparation of future sites for implants. Int J Oral Maxillofac Implants. 1999 Jul-Aug;14(4):529-35.

20. Anitua E, Sánchez M, Orive G. Potential of endogenous regenerative technology for in situ regenerative medicine. Adv Drug Deliv Rev. 2010 Jun;62(7-8):741-52. https://doi.org/10.1016/i.addr.2010.01.001

21. Caton JG, Armitage G, Berglundh T, Chapple IL, Jepsen S, Kornman KS, et al. A new classification scheme for periodontal and periimplant diseases and conditions - Introduction and key changes from the 1999 classification. J Clin Periodontol. 2018 Jun;45 Suppl 20:S1-8. https://doi.org/10.1111/jcpe.12935

22. Silness J, Loe H. PERIODONTAL DISEASE IN PREGNANCY. II. CORRELATION BETWEEN ORAL HYGIENE AND PERIODONTAL CONDTION. Acta Odontol Scand. 1964 Feb;22(1):121-35. https://doi.org/10.3109/00016356408993968

23. Mühlemann HR, Son S. Gingival sulcus bleeding: a leading symptom in initial gingivitis. Helv Odontol Acta. 1971 Oct;15(2):107-13.

24. Moradi O., Ghamsari SM., Dehghan MM., Sedaghat R., Akbarein H. Effects of platelet rich plasma (PRP) and platelet rich growth factor (PRGF $\left.{ }^{\circledR}\right)$ on the wound healing of distal part of limbs in horses. Iran J Vet Surg. 2013;8(1);Serial 18.

25. López-Jornet P, Camacho-Alonso F, Molina-Miñano F, Vicente-Ortega V. Effects of plasma rich in growth factors on wound healing of the tongue. Experimental study on rabbits. Med Oral Patol Oral Cir Bucal. 2009 Sep;14(9):e425-8.

26. Vahabi S, Vaziri S, Torshabi M, Rezaei Esfahrood Z. Effects of Plasma Rich in Growth Factors and Platelet-Rich Fibrin on Proliferation and Viability of Human Gingival Fibroblasts. J Dent (Tehran). 2015 Jul;12(7):504-12.

27. Bayer A, Tohidnezhad M, Lammel J, Lippross S, Behrendt P, Klüter T, et al. Platelet-Released Growth Factors Induce Differentiation of Primary Keratinocytes. Mediators Inflamm. 2017;2017:5671615. https://doi.org/10.1155/2017/5671615 
- Plasma rich in growth factors (PRGF) in non-surgical periodontal therapy: a randomized clinical trial

28. Anitua E, Sanchez M, Merayo-Lloves J, De la Fuente M, Muruzabal F, Orive G. Plasma rich in growth factors (PRGF-Endoret) stimulates proliferation and migration of primary keratocytes and conjunctival fibroblasts and inhibits and reverts TGF-betal-Induced myodifferentiation. Invest Ophthalmol Vis Sci. 2011 Aug;52(9):6066-73. https://doi.org/10.1167/iovs.11-7302

29. Brini AT, Ceci C, Taschieri S, Niada S, Lolato A, Giannasi C, et al. Effect of an Activated Platelet Concentrate on Differentiated Cells Involved in Tissue Healing. J Craniofac Surg. 2016 May;27(3):656-61. https://doi.org/10.1097/SCS.0000000000002540

30. Nishiyama K, Okudera T, Watanabe T, Isobe K, Suzuki M, Masuki H, et al. Basic characteristics of plasma rich in growth factors (PRGF): blood cell components and biological effects. Clin Exp Dent Res. 2016 Mar;2(2):96-103. https://doi.org/10.1002/cre2.26

31. Anitua E, Alonso R, Girbau C, Aguirre JJ, Muruzabal F, Orive G. Antibacterial effect of plasma rich in growth factors (PRGF $($ Endoret ${ }^{\circledR}$ ) against Staphylococcus aureus and Staphylococcus epidermidis strains. Clin Exp Dermatol. 2012 Aug;37(6):652-7. https://doi.org/10.1111/j.1365-2230.2011.04303.x

32. Drago L, Bortolin M, Vassena C, Taschieri S, Del Fabbro M. Antimicrobial activity of pure platelet-rich plasma against microorganisms isolated from oral cavity. BMC Microbiol. 2013 Feb;13(1):47. https://doi.org/10.1186/1471-2180-13-47

33. Drago L, Bortolin M, Vassena C, Romanò CL, Taschieri S, Del Fabbro M. Plasma components and platelet activation are essential for the antimicrobial properties of autologous platelet-rich plasma: an in vitro study. PLoS One. 2014 Sep;9(9):e107813. https://doi.org/10.1371/journal.pone.0107813

34. Abdul Ameer LA, Raheem ZJ, Abdulrazaq SS, Ali BG, Nasser MM, Khairi AW. The anti-inflammatory effect of the platelet-rich plasma in the periodontal pocket. Eur J Dent. 2018 Oct-Dec;12(4):528-31. https://doi.org/10.4103/ejd.ejd_49_18

35. Panda S, Sankari M, Satpathy A, Jayakumar D, Mozzati M, Mortellaro C, et al. Adjunctive effect of autologus plateletrich fibrin to barrier membrane in the treatment of periodontal intrabony defects. J Craniofac Surg. 2016 May;27(3):691-6. https://doi.org/10.1097/SCS.0000000000002524

36. Panda S, Ramamoorthi S, Jayakumar ND, Sankari M, Varghese SS. Platelet rich fibrin and alloplast in the treatment of intrabony defect. J Pharm Bioallied Sci. 2014 Apr;6(2):127-31. https://doi.org/10.4103/0975-7406.129178

37. Panda S, Jayakumar ND, Sankari M, Varghese SS, Kumar DS. Platelet rich fibrin and xenograft in treatment of intrabony defect. Contemp Clin Dent. 2014 Oct;5(4):550-4. https://doi.org/10.4103/0976-237X.142830

38. Panda S, Del Fabbro M, Satpathy A, Das AC. Pedicled buccal fat pad graft for root coverage in severe gingival recession defect. J Indian Soc Periodontol. 2016 Mar-Apr;20(2):216-9. https://doi.org/10.4103/0972-124X.170844

39. Del Fabbro M, Lolato A, Panda S, Corbella S, Satpathy A, Das AC, et al. Methodological quality assessment of systematic reviews on autologous platelet concentrates for the treatment of periodontal defects. J Evid Based Dent Pract. 2017 Sep;17(3):239-55. https://doi.org/10.1016/i.jebdp.2017.04.006

40. Sharma A, Pradeep AR. Treatment of 3-wall intrabony defects in patients with chronic periodontitis with autologous platelet-rich fibrin: a randomized controlled clinical trial. J Periodontol. 2011 Dec;82(12):1705-12. https://doi.org/10.1902/jop.2011.110075 